\title{
The Formation Mechanism of High-Steep Slopes Composed of Huge Thick Loose Layer in the Strong Uplift Area of the Qinghai-Tibet Plateau
}

\author{
Bo Luo \\ (The first highway survey and Design Institute Co. Ltd., Xi'an , 710054, China) \\ 362889139@qq.com
}

Keywords: Qinghai-Tibet Plateau; Loose deposition; Disaster; High-steep slope; Formation mechanism

\begin{abstract}
There exist many high-steep slopes composed of huge thick loose layer in part of (especially in the southeast of) the Qinghai-Tibet Plateau which is uplifting strongly, they are the development basis of large geological disasters such as landslide or debris flows. The slopes are the result of comprehensive effect of many loose deposition generated form crustal uplift effect 、 mountain hazards effect such as large landslides and debris flows centrally handling accumulation and river sharp erosion slice effect.
\end{abstract}

\section{Introduction}

The strong uplift of Qinghai-Tibet Plateau resulted in the frequent occurrence of faulting, earthquakes, storms, glaciers, geothermal and a series of events in this area, at the same time caused a number of major geological disasters which have big differences with the geological disasters in the mainland. In Sichuan-Tibet highway in Tibet, which is $427 \mathrm{~km}$ in total from Nyingchi to Basu, where developed 204 various types of geological disasters, which means every $2 \mathrm{~km}$ along the road there is a collapse, landslides, mudslides and other disasters point. The 102-108 track section of the Sichuan-Tibet Highway that the disaster extremely developed is $60 \mathrm{~km}$ long in total, and there are 21 mudslides and 20 landslides developed in there. And the type of the disaster includes not only collapse, landslides and mudslides, but also sharper slipped slope, the rolling stones, snow and landslides with region characteristics. Among them, there are the very famous Yigong catastrophic landslides, 102 landslide group, the Dongjiu landslide group, Layue collapse, Peilong ditch mudslides, Guxiang mudslides and Maqimeigou mudslides and other disasters, and the amount of each disasters is hundreds or even a ten million cubic meters. These variety and huge disasters is mostly generated by the presence of loose deposits with thick layer and other factors latter.

\section{Formation Mechanism of Loose Material-Crustal Uplift Effect}

Because of the collision, extrusion and long-term wedging between the Indian plate and the Eurasian plate, there intermittently appeared three distinct stages of uplift from slow upright to moderate uplift and then the rapid uplift of the Qinghai-Tibet Plateau since Eocene (50Ma \pm ). Especially in the extremely rapid uplift since $0.5 \mathrm{Ma}$, the uplifting speed reaches to $4.5 \mathrm{~mm} / \mathrm{a}$. The large scale, phased uplift caused the formation of not only the current unique landscape of the Qinghai-Tibet Plateau with an average elevation of over $4000 \mathrm{~m}$, but also a distribution of a large number of loose deposits at the same time. In other words, the large-scale, phased uplift caused the crustal uplift effect of the loose materials.

This is mainly reflected in the following aspects: a. The strong uplift formed a large area of mountain, which effectively increased the unloading and various weathering; $b$. The strong uplift changed regional climate, accelerated the circulation of the Earth's surface, enhanced the erosion, leaching and dissolution of water; $c$. The high attitude caused by the uplift resulted in the enhance of the effect of freezing and thawing and glaciers and strengthen the mechanical erosion of continental 
crust as well. d. The upright caused the frequent occurrence of regional tectonic activity and earthquakes, and also made the bedrock dislocation or broken and the unstable mountain collapsed which produced loose deposits. e. Tectonic movements caused by the uplift lead to massive made hot events and high-grade metamorphism and partial melting which made chemical weathering significantly increased. The overall result of these effects greatly enhanced weathering rates of plateau substances, accelerated broken rates of rock, so there appeared a lot of loose deposits on the top of the plateau, especially in the slope zone.

\section{Transport and Accumulation Mechanism of Loose Material-Mountain Hazards Effect}

As mentioned above, the uplift of the Qinghai-Tibet Plateau leads to a variety of weathering effect enhancement of the area. Plenty of residual material caused of this phenomenon is present all over the surface of the slope. In addition to transport and accumulation of the normal flow, there are glaciers, mudslides and landslides, and other geological disasters developed in the research area that has obvious characteristics on centralized transport in this area and usually form loose deposits with thick layer.

Glacial Deposits. Since the Quaternary, glacial activity occurred many times in Polongzangbu river basin. Among these times, only the moraine layer in the penultimate glacial maximum and the last glacial maximum 12.5 to 7.3 million years ago is the one that not only the ancient glaciers has been preserved today, but also we could determine the size of glaciers at that time. The moraine layer in the penultimate glacial maximum can be found in the main river downstream of evidence, at the same time, the moraine layer in the last glacial maximum can be only found in the upper reaches of the large tributary of the river. For example, the ancient moraine layer in the lower part of the 102 large landslide in the Polongzangbu river downstream is $256.4 \mathrm{~m}$ thick, while the ancient moraine layer in the right bank of the Peilong ditch river downstream is $310 \mathrm{~m}$ thick. And the total volume of the two is $1.0 \times 10^{8} \mathrm{~m}^{3}$.

In addition, there are 1861 modern marine glaciers with a total area of $4638.42 \mathrm{~km}^{2}$ developed in this area. These modern maritime glacier changes with climate change. The changes lead to new ice avalanches, glacier avalanches, glacial lake outburst floods and debris flows and other disasters, and there formed new centralized loose deposits with thick layer in the river valley.

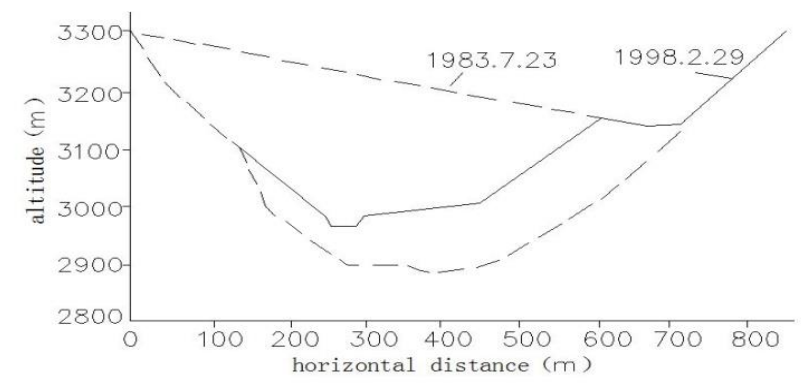

Fig. 1 The cross-section diagram of ice and snow slumping and accumulating in Peilong ditch on 28, July, 1983.

[According to document 1]

Massive snow slump took place at the hanging glacier ditch in the west bank of Peilong ditch head which is the end of the modern glacier on July 28, 1983. The snow slump lead to the occur of 260 meters high deposit(fig. 1) composed of ice, rock and ice deposits that is extending down about $3 \mathrm{~km}$, and glacial lake formed upstream with a volume of about $5.0 \times 10^{6} \mathrm{~m}^{3}$. The glacial lake outburst and become a large debris flow at around 22:00pm on that day. On June 17-18, 1984, the hanging glacier appeared a large avalanche. It not only formed snow slumping mass with a height of about $230 \mathrm{~m}$ and a maximum width of $1100 \mathrm{~m}$, but also lead to the largest debris flow in the 80 s in the gully. The avalanche blocked Polongzangbu half an hour, and the water flew back over the Tongmai Bridge. 
Landslide Collapse Accumulation. Due to the effect of the rising crust, tectonic activity, the ice melted, earthquake-prone, rain and other things, various collapse landslide hazards in the study area are well developed, and they are very huge. These collapse landslide hazards often quickly piling up loose deposits with thick layers in the local area.

At 20 o 'clock on April 9, 2000, Zhamunongba, the tributaries of Polongzangbu river basin appeared a catastrophic collapse-landslides-debris flow. This disaster is resulted by the mountain collapse with an altitude of $4500 \sim 5300 \mathrm{~m}$. the volume of the collapse is about $3.0 \times 10^{7} \mathrm{~m}^{3}$ while the vertical drop height is $2580 \mathrm{~m}$. The powerful impact of it made the body of collapse disintegrate and also corroded (cut) abundant loose deposits in the gully and bedrock with poor stability on both sides of the gully. The disintegrating made the collapse thing migrated to Yigongzangbu with an altitude of only $2190 \mathrm{~m}$ with the average speed of $37 \sim 39 \mathrm{~m} / \mathrm{s}$, then they blocked the entire river and formed a natural gravel dam with a length of $3.2 \mathrm{~km}$, a width of $1.2 \sim 2.5 \mathrm{~km}$, the maximum thickness $140 \mathrm{~m}$ and the minimum thickness $75 \mathrm{~m}$. The whole debris surface area is about $11.6 \mathrm{~km}^{2}$, total volume is about $5.1 \times 10^{8} \mathrm{~m}^{3}$.The deposits dam made upstream water of the lake rise daily to $0.95 \mathrm{~m}$ in height. The submerged range of it is up to $51.9 \mathrm{~km}^{2}$ [6]. 62 days later, the deposits dam outburst that formed a super-large scale flood. The instantaneous flow of flood up to $124000 \mathrm{~m}^{3} / \mathrm{s}$ at most, and the flood peak last for 6 hours. The flood destroyed all the bridges, transportation and communication facilities in Yigongzangbu, Polongzangbu, Brahmaputra River and it's both sides, and also made inhabitants who live in the downstream range along the river get injured [6].

The hazard is controlled by regional strong rise, abundant rainfall and faults and other factors and affected by terrain conditions, stratum structure, physical and mechanical properties of rock mass, native rock structural plane and secondary fractures conditioned by freeze-thaw effect and other factors. It appeared due to the excess melt water and its large scale and serious harm are rare at home and abroad. The hazard finally made the flood corrode the valley and the slope toe, which caused hundreds of kilometers valleys toes lost stability in different degrees and this made the collapse, landslide occurred on both sides of the valley along the rivers. In the end, the shallow pull-type landslide zone and other secondary geological disasters rose up. Besides, the hazard left tens of meters thick, loose deposits in the original river. The sediments are about 20 meters thick in the interchange-Tongmai between Yigongzangbu and Polongzangbu bridges which is about 20 meters away from the landslide downstream. There are loose sand piled up to 10 15 meters high overnight that in the depression zone where the two rivers and intersected. The partition map of e the appearance of Yigong big slump material flow is shown in fig. 2.

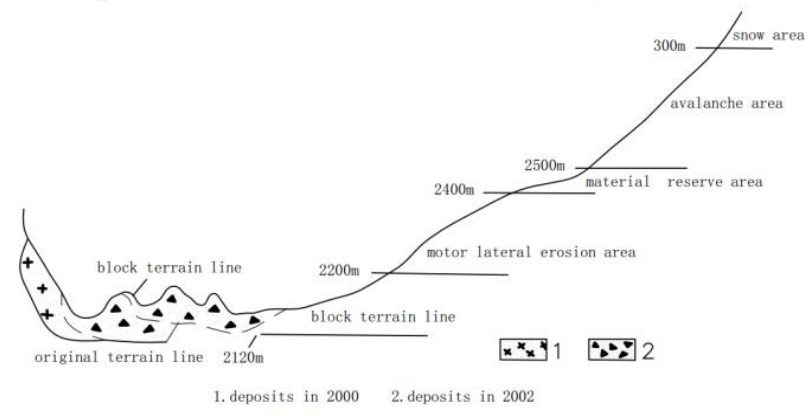

Fig. 2 The zone figure of material flow happening in Yigong huge landslide. [According to document 5]

Debris Flow Deposits. Due to the ice and snow melt, abundant rainfall, narrow valleys with large grade and exist of abundant varies loose materials as we mentioned above, this area often occur various types, different sizes of debris flows. These debris flows made the loose deposits widespread in the gutter centralized handled and accumulated to exit of ditch and flat zone, and formed loose accumulation with thicker layer. 
Polongzangbu, which we mentioned above, formed glacial lake because a lot of loose material caused by the snow slump blocked the valley. The outburst of glacial lake resulted in the outbreak of super-large scale of glacial debris flow lasted in three years which are 1983, 1984 and 1985. The debris flow blocked the main stream of Polongzangbu river, and formed a lake with the length of 16.5 meters, the maximum width of 220 meters and the maximum depth of 14.3 meters. That made the

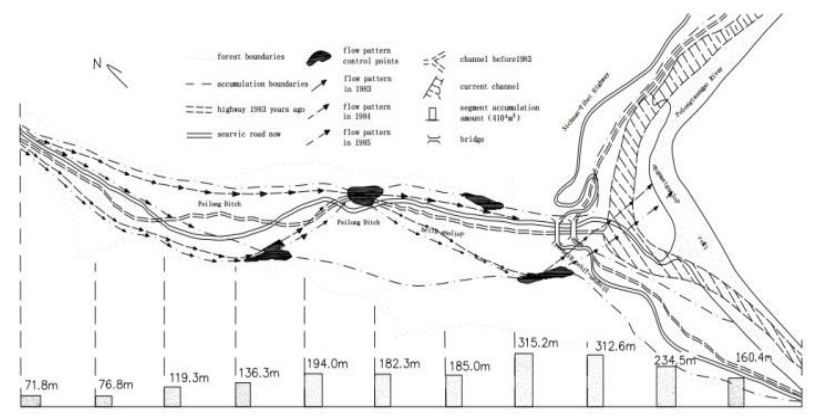

Fig. 3 The schematic diagram of the accumulation range and the streaming potential of debris flow in Peilong ditch. [According to document 1]

backwater submerge the road near 7.0 kilometers, more than 80 vehicles be in disaster, several people die, billions of economic losses. A large number of solid matter brought by the debris flow blocked in riverbed, that make the whole river bed raised 10 meters. The maximum height of silt blocking the river is up to $29.3 \mathrm{~m}$. Except for the plentiful loose material washed away by the Polongzangbu river which was carried by the debris flow, the loose debris stranded in the downstream valleys has a volume of $1.28 \times 10^{7} \mathrm{~m}^{3}$, and the loose debris in the front part of the alluvial fan has a volume of $7.08 \times 10^{6} \mathrm{~m}^{3}$. Fig. 3 shows the scope, flow pattern, thickness of the loose materials of the debris flow in this gully.

\section{Formation Mechanism of High Steep Slope-River Erosion Incised Effect}

As mentioned above, the Qinghai-Tibet Plateau had strong uplift caused by collision compression between the India plate and Eurasian plate, and the uplift has a tendency to become faster. Since 3 million years ago, the vertical ascent rate of the study area was $3 \mathrm{~mm} / \mathrm{a}$, since the last ice age up to $6.2 \mathrm{~mm} / \mathrm{a}$ [7].

In addition, Palongzangbu basin is located in southeastern of Qinghai-Tibet Plateau, the climate controlled by the total circulation situation of the Qinghai-Tibet Plateau, which belongs to the north margin of subtropical mountain climate, semi humid climate region of Qinghai-Tibet Plateau. Because of the effect of the India ocean wet heating airflow going north along the Brahmaputra, the climate of the area is mild, humid, the spring and autumn are connected together without summer, the difference of temperature between summer and winter is relatively small, high rainfall, generally with the characteristics of continuous rainy, long but not intensity rainstorm days, more precipitation days(>200 days), and with the increasing of altitude, the precipitation increase. Such as in the downstream(altitude $<2000 \mathrm{~m}$ ), the annual average temperature is about $15.5^{\circ} \mathrm{C}$, the Maqimei $\operatorname{ditch}\left(2182 \mathrm{~m}\right.$ above sea level) is $11.9^{\circ} \mathrm{C}$, Bomi $\left(2736 \mathrm{~m}\right.$ above sea level) is $8 .^{\circ} \mathrm{C}$. The corresponding average annual precipitation is respectively $1750.0,1086.0,1906.5 \mathrm{~mm}$. In this place, not only the development scale of warm glacier is larger, but the seasonal snow covering is also considerable. In the period of melting in summer, heat income is reflected that turbulent exchange and condensation heat release are both higher than continental glacier, while the heat of evaporation in the caloric expenditure decreases significantly, resulting in much glacial melt water runoff. According to the study of Lanzhou Institute of glaciers, in marine glacier area southeast of Tibet, 96.9\% thermal balance is used for melting the glaciers. This not only because of the direct solar radiation, but more 
important reason is the humidity of marine glacier area is high, turbulent thermal take a large proportion.

So rich rain and snow melt water, and the strong rise in the earth's crust, makes Polongzangbu basin becomes one of the world's strongest soil erosion, the largest watershed elevation area. There are high mountains ravines, cross-strait valley which is several hundred meters high, even kilometers, and the valley is narrow, the water flow fast. And the aforementioned huge thick loose deposits rapidly piling up by geological disasters, such as glacier, landslide and mud-rock flow are more likely to erosion, forming ten meters to hundreds of meters high and steep loose slope. Fig. 4 is the erosion condition of the hometown debris formed by mud-rock flow.

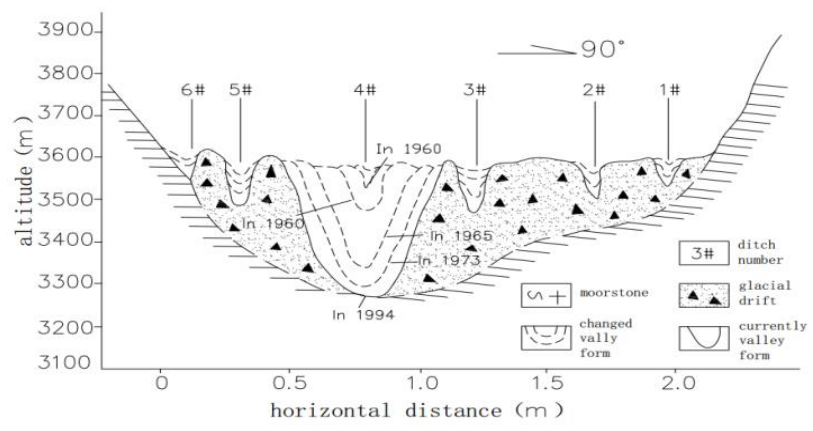

Fig. 4 The schematic diagram of the debris flow deposition's erosion and changing in hometown. [According to document 1]

\section{Conclusions}

High steep slopes with the very thick layer exist on local area in the strong uplift Qinghai-Tibet Plateau is caused by the comprehensive action composed of the earth's crust uplift effect, mountain disaster effect and rivers sharply incised effect. That means:

(1)The strong crustal uplift lead to the enhancement of the formation of mountain, climate change, water erosion, and various physical and chemical weathering, crustal uplift effect which produced a large amount of loose materials.

(2)The frequent activity of large landslides, mudslides and other mountain hazards made the loose materials mentioned above centralized handling, and formed very thick layers accumulated mountain hazards effect in the local area.

(3) Abundant precipitation, ice and snow melt water in local area and great gradient made the river formed by high steep slopes appeared eroded sharply incised effect.

\section{References}

[1] Chinese Academy of Sciences, Institute of Mountain Hazards and Environment, CAS and Xizang Autonomous Region communications Science Research Institute: Research on Typical Mountain Hazards of Sichuan-Tibet Highway (Chengdu University of Science and Technology Press, Chengdu, China 1999).

[2] J. Chen etc: The Continental Weathering and The Global Climatic Change. Advances in earth science, Vol. 16 (2001. 6) No.3.

[3] R.S. Fu, L.G Li, J.H. Huang and R.M. Xu: Three-Step Model Of The Qinghai-Xizang Plateau Uplift. Chinese Journal of Geophysics (1999.9), p.609.

[4] The Chinese Academy of Science Qinghai-Xizang Plateau Comprehensive science expedition: Xizang Quaternary Geology (Science Press, Beijing, China 1983). 
[5] P.Y. Zhu, C.H. Wang and B.X. Tang: The Deposition Characteristic of Supper Debris Flow in Tibet. Journal of Mountain Science (2000. 10), p.453.

[6] W. Liu: Study on the characteristics of huge scale-super high speed-long distance landslide chain in Yigong, Tibet. The Chinese Journal of Geological Hazard and Control (2002.9) p.9.

[7] D.L. Zhong and L. Ding: Discuss on the Qinghai-Xizang Plateau Uplift Process and its Mechanism of the Science in China, 1996,26(4):289-295, p.289.

[8] Ahn B S, Park K S, Han C H etc: Multi-attribute decision and under inomplete information and erarchical structure. European Journal of Operational Research, 2000, 125(2), p.431.

[9] Kiyotada Hayashi: Multi-Criteria Aid for Agricultural Decision using Peference Relations: Methodology and Application. Agricultural System, 1998. 58(4), p.483.

[10]Q.M. Xie and Y.Y. Xia: An improved hierarchy decision making model for the treatment of rock mass slope[A]. Proc. Of the 2nd Int. Conf. on New evelopment in Rock Mechanics \& Rock engineering (Rintan Press, USA 2002), p.445. 